\title{
Bequeme Vorrichtungen zum Nachfüllen von (namentlich
} oxydablen) Titerflüssigkeiten.

(Nachträgliche Mittheilung ans dem Laboratorium der westfälischen Berggewerkschaftskasse, Bochum, Nov. 1873.)

Von

\section{Albert Sauer.}

(Hierzu Fig. 4 auf Taf. III.)

Die beliebig grosse Flasche A steht durch das Robr $\mathrm{c} c$ wie aus der Zeichnung Fig. 4 Taf. III des Näheren ersichtlich, mit der Bürette in Verbindung. Zum Zwecke des Füllens öffnet man den Hahn $d$ und den Quetschhahn $f$ und saugt durch den Schlauch $g$ die Flüssigkeit in die Bürette. Hierbei tritt gleichzeitig der von mir früher beschriebene kleine Apparat $\mathrm{B}_{1}{ }^{*}$ ) (diese Zeitschr. 12, 177) in Thätigkeit. Das Nachfüllen erfolgt einfach durch Oeffnen der Hähne d und f. Am Ende einer Versuchsreihe entleert man die Bürette (nachdem man dieselbe nochmals ganz gefüllt hat um die Luft zu verdrängen) durch aus einem $\mathrm{K}$ ip p'schen Apparat $\mathrm{K}$ entwickelte Kohlensäure; hierbei schliesst man dessen obere Oeffnung $\mathrm{h}$ mit der Hand so lange, bis Kohlensäure in die Flasche $\mathrm{A}$ tritt. Auf gleiche Weise lässt sich die Bürette vor Beginn einer Versuchsreihe durch mehrmaliges Füllen und Entleeren mit dem Inhalt der Flasche A ausspülen und derselbe durch den Kohlensäurestrom mischen.

\section{Ein neues Volumenometer. \\ Von}

\section{Albert Sauer.}

(Hierzu Fig. 5-9 auf Taf. III.)

Mit Zuhülfenahme der in der vorhergehenden Mittheilung beschriebenen Bürette habe ich ein Volumenometer construirt. Fig. 5 Taf. III.

Das untere Knierohr der Bürette ist durch Gummischlauch mit dem Ansatzrohr des Gefässes $H$ verbunden. Dieses trägt einen eingeschliffenen Stopfen, dessen Einrichtung aus der besonderen Zeichnung Fig. 6 ersichtlich ist, die seitliche Oeffnung $\mathbf{x}$ des eingeschmolzenen Rohres hat

*) Als Säuregefäss wende ich jetzt ein Pulverglas an, welches zur Verhütung von Uebersteigen nach $A$ nicht mehr Säure fasst, als die mit Marmor beschickte Kempf'sche Waschflasche. Die Säureflasche trägt einen doppelt durchbohrten, oder mit Schlitz versehenen Kork. $\mathbf{T}$ ist ein Chlorcalciumrohr. 